\title{
Poder, emprego e política econômica
}

\author{
RUBENS R. SAWAYA I
}

\section{Introdução}

A

DISCUSSÃo sobre o desemprego na economia brasileira - e as políticas econômicas ante o problema - envolve um debate bem mais amplo, teórico, sobre como funciona a economia. Tornaram-se claras as linhas de pensamento econômico nesse debate, foco deste artigo. Apesar de tomar a aparência de algo teórico, as ações e os resultados são concretos e tornam, por isso, o debate antes político. Não se trata de uma divergência entre partidos políticos uma vez que hoje as ideias e medidas se misturam dado que diferentes partidos adotam medidas parecidas, quando não iguais. O problema é político, uma vez que envolve interesses específicos de grupos da sociedade, mas não partidário.

O Brasil nos últimos anos apresentou um crescimento significativo como há décadas (desde os anos 1970) não se via. Cheio de contradições internas, promoveu um amplo crescimento do emprego, da renda com políticas de investimentos públicos (Programa de Aceleração do Crescimento - PAC) e sociais que modificaram as características do país. Esse processo foi bloqueado por problemas internos e externos, por falhas e dificuldades de condução, o que abriu espaço para críticas e pressões exercidas por interesses de grupos econômicos.

Este artigo tem por objetivo demonstrar que, apesar dos reais problemas que a economia brasileira passou nos últimos anos e passa hoje, o que de fato impede a continuidade do crescimento econômico e do emprego são decisões políticas baseadas em determinada visão do funcionamento da economia. Essas políticas estão fundadas em bases teóricas presentes nos modelos ortodoxos apresentados nos "manuais de economia" importados. Apesar de sua aparência técnica, no fundo servem a determinados interesses ligados à disputa pela renda e não ao real crescimento econômico com distribuição de renda. São essas teorias importadas, utilizadas de forma oportunista em uma aliança específica de classes, que impedem e dificultam a real transformação do Brasil. Essa base teórica vem pela captura intelectual de um grupo de economistas que funcionam como ideólogos do bloco de poder e disseminam a "teoria ortodoxa" como técnica e correta. Foram, como observa Bresser-Pereira (2014, p.309), capturados diretamente nas universidades, "aparelho ideológico chave de dominação" e levados "a fazerem seus PHDs em universidades estrangeiras [...] estudando economia, ...dominadas pelo ideário neoliberal". São esses economistas cooptados pela estrutura de poder que ocupam a burocracia estatal e definem as políticas econômicas que geram desemprego. 
Essa visão teórica aponta que os gastos públicos "excessivos" (sociais) teriam subvertido a "boa teoria" fundada nas "leis da natureza" e, assim, retirado o "mercado de trabalho" de seu equilíbrio "natural" e o crescimento do PIB de seu "potencial". O governo foi acusado de subverter as "taxas naturais de desemprego", o que teria causado crescimento do PIB acima de seu potencial e pressões salariais. Mesmo que pouco se refletisse em taxas de inflação, o monstro que não existia foi anunciado aos gritos - na imprensa - como se quisessem mesmo acordá-lo. O monstro apareceu estranhamente após as políticas recessivas colocarem a economia de joelhos, e não antes. Ao invés de recuperar a subjetiva credibilidade, jogou o Brasil na mais profunda recessão sem mexer de fato com o problema original: o crescimento com importação e desindustrialização. Freiam-se as importações, mas com brutal recessão.

Nos últimos dez anos essa forma de pensar esteve presente no pacto adotado, que conviveu até certo ponto com as mudanças pontuais e as políticas sociais, principalmente em função do crescimento econômico e do boom de commodities. Agora esse pacto foi rompido, abrindo espaço para amplo crescimento da ortodoxia como pensamento hegemônico.

Nas economias capitalistas, principalmente naquelas em que a renda é altamente concentrada, a solução para uma melhor distribuição historicamente ocorre por um grande salto para a frente. O crescimento do PIB e a criação de empregos em simultâneo com aumento do valor excedente é a conjunção que pode melhorar o padrão de vida das pessoas. A desaceleração econômica acirra as disputas pela riqueza com predomínio daqueles grupos sociais que possuem maior poder e controle sobre ela (bancos e corporações), bem como sobre a estrutura de poder que constitui o Estado.

\section{Crise atual e emprego}

Nos últimos dez anos a taxa de desemprego declinou de forma consistente. Passou de uma média de 11,5\% em 2004 para 4,8\% em 2014 (IBGE, taxa média de desocupação) números pouco afetados pela grande queda na atividade econômica em 2009. O rendimento médio real do trabalho cresceu 35\% no mesmo período (IBGE, pesquisa mensal do emprego). O crescimento do PIB foi persistente entre 2004 até pelo menos 2010, quando atingiu a marca de $7,5 \%$, começando a declinar a partir de 2011 , mas sem impacto sobre o emprego e a renda até 2014. É bom lembrar que as taxas de inflação, apesar de estarem no teto da meta estabelecida pelo Banco Central, mantiveram-se estáveis em torno de $6,5 \%$ ao ano até fins de 2014. A dívida líquida do setor público consolidada caiu de uma média de $54,5 \%$ sobre o PIB para $35 \%$ (Banco Central do Brasil) no mesmo período. A dívida bruta caiu de 70,6\% do PIB em 2004 para valores entre $60 \%$ e $64 \%$, elevando-se ligeiramente entre 2008 e 2014, movimento relacionado à queda no crescimento e arrecadação, bem como pela reversão da política de diminuição das taxas de juros.

A queda nas taxas de crescimento do PIB a partir de 2011 reflete uma 
reversão das políticas no governo Dilma em relação ao governo Lula em razão da modificação do cenário internacional, principalmente por conta da queda nos preços das commodities, base central das exportações brasileiras (e de nossos vizinhos na América do Sul). A política de cortes de gastos públicos, logo no início daquele ano, sinalizou a desaceleração da economia. De outro lado, a queda nos preços das commodities serviu para demonstrar a fragilidade da estratégia crescimento do consumo e da renda internos sem crescimento relativo da indústria, com reflexos sobre a elevação das importações. As exportações de manufaturados que se destinavam principalmente para a América Latina também desaceleram. A queda nos preços das commodities afetou a todos os países da região que haviam se beneficiado do boom exportador.

Com vinte anos de Real valorizado e ascensão da China, a indústria se beneficiou pouco do crescimento da década. Refletiu a falta de uma política específica com reflexos negativos sobre os empregos no setor que possui forte efeito multiplicador e distributivo sobre a economia. O início da política de desvalorização tardia da moeda nacional com a economia já em desaceleração em 2011 - algo que deveria ter sido feito quando a economia crescia para incentivar a produção industrial interna, o que teria menor impacto inflacionário - passou a atrapalhar e a pressionar preços via repasse de custos por parte das empresas. Com a economia desacelerando-se, poucas empresas estavam dispostas a investir na substituição de importações. A diminuição das taxas de juros ao longo de 2012 - que imaginava uma reação positiva automática dos investimentos industriais - serviu apenas para enfurecer o mercado financeiro e os rentistas e por isso foi rapidamente revertida. A atividade econômica decresceu continuamente.

Mesmo nesse cenário de desaceleração, as taxas de desemprego continuaram a baixar até 2014 , a renda média real continuou a crescer - principalmente por conta da expansão do setor de serviços - enquanto a inflação permaneceu relativamente estável. Depois de manter positivo ao longo de vinte anos, em 2014 o superávit primário do setor público caiu, mas pouco, e tornou-se déficit em dezembro (-0,6\% do PIB em 2014). Às vésperas das eleições, esse fato foi o suficiente para acusar o governo de "descalabro" fiscal quando, na verdade, o déficit era o resultado da desaceleração da arrecadação devido à queda no próprio crescimento da economia e não de aumento dos gastos públicos.

Problemas nas contas externas começam a aparecer em 2012-2013 diante da queda dos preços das commodities. Estava claro que era o momento de rever a estratégia, retomar o Programa de Aceleração do Crescimento, para fornecer sinais positivos às empresas e, assim, puxar os investimentos, principalmente industrial, inclusive com substituição de importações, gradativamente desmontando a pressão importadora. Mas não foi isso que ocorreu até 2014. A economia permaneceu em desaceleração contínua com perda de credibilidade.

Em 2015, por pressões políticas ou por erros de condução, a decisão foi implantar uma fortíssima política recessiva, fato que já vinha sendo sinalizado 
desde o final do mandato em 2014. A ortodoxia e determinados interesses haviam vencido a heterodoxia que propunha um salto para frente como solução. A opção pela manutenção do emprego e da renda e a correção de rota ante a reversão na situação internacional que impactou o Balanço Comercial brasileiro foi substituída por uma brutal recessão criada pela política econômica adotada.

A política recessiva fabricada já mostra seus impactos sobre o emprego e a renda. Juros elevados sobre títulos públicos implicam uma forte transferência de renda para aos rentistas atingidos volumes já se aproximam de $8 \%$ do PIB, ante o histórico de $5 \%$ dos últimos anos. ${ }^{1}$ Assim, a nova política, a despeito de seu anunciado objetivo de combater a inflação que agora se torna ascendente, promove uma enorme concentração de renda com queda nos salários reais. Adicionalmente, o foco do momento passou a ser criticar a Constituição de $1988^{2}$ que teria ampliado em demasia os direitos sociais em relação à capacidade de gasto do Estado. O objetivo é gerar superávits primários para pagar juros elevados e não gastos sociais.

Com uma teoria econômica travestida de técnica, fundada em uma matemática que assusta os leigos, mas é motivo de piada aos físicos, a ortodoxia serve a seu papel de determinar com quem fica e quem se beneficia da renda nacional. Precisou transformar, midiaticamente, uma inflação estável de 6,5\% ao ano em um monstro hiperinflacionário. Além disso, também colocou uma enorme lente de aumento em um prenúncio de déficit público diante de uma dívida pública bastante baixa em relação a quase todos os países do mundo, anunciando um "descalabro fiscal". Hoje, após a forte desaceleração imposta sobre a economia, a inflação aponta para uma taxa de $10 \%$ anualizada e crescente, com um crescimento do PIB negativo que talvez ultrapasse $-2 \%$ em 2015, uma taxa de desemprego crescente e, pior, nenhum sinal de "recuperação da credibilidade" que a base teórica que fundamenta a política adotada prometia.

\section{Emprego, mercado de trabalho e salário: a questão teórica}

O debate sobre a questão do desemprego é amplo e histórico na literatura econômica e está no centro da discussão entre as correntes de pensamento. Está na base estruturante do pensamento ortodoxo e se materializa na política de metas de inflação fundada no equilíbrio das "taxas naturais" de emprego e produto, o que impede a intervenção pública sob o risco de quebrar a "credibilidade" que compõe a natureza psicológica dos agentes. Sua base se origina na recuperação da ideia de que força de trabalho é uma mercadoria comprada e vendida por um preço definido por forças de oferta e demanda. Remonta ao século XIX e foi amplamente debatida por Marx e Keynes. Essas ideias foram recuperadas pelo pensamento novo-clássico ao incorporar a taxa de desemprego natural de Friedman em sua crítica à curva de Phillips (Friedman 1988, p.389) do keynesianismo ortodoxo ${ }^{3}$ (veja o debate em Snowdon e Vaine, 2005).

Com a persistência de taxas de desemprego elevadas no mundo real, o próprio keynesianismo ortodoxo modificou o conceito de "pleno emprego" dis- 
cutido por Keynes, para um conceito fundado na Curva de Phillips definindo-o como aquele nível que não acelere a inflação. Assim, admitia um desemprego "normal" dentro do equilíbrio entre oferta e demanda de trabalho no conceito clássico. Elevações na demanda de emprego com a oferta restrita criariam pressões salariais por parte dos trabalhadores (como no mercado de mercadorias), custos adicionais que os empresários repassariam automaticamente aos seus preços, criando pressões inflacionárias. Assim, existiria uma taxa de desemprego necessária não inflacionária (Lavoie, 2006, p.13).

Para o pensamento novo-clássico, seguindo Friedman, nem mesmo essa lógica seria válida. Apela para a "racionalidade" microeconômica dos trabalhadores que ofertariam trabalho em razão dos seus salários reais (poder de compra), tomando autonomamente a decisão de trabalhar ou não com base em uma troca racional intertemporal entre renda e lazer (Snowdon; Vane, 2005, p.XX; Lavoie, 1992, p.219). Portanto, decidem quanto de emprego ofertam. Isso significa que existe uma "taxa de desemprego natural", definida pelos trabalhadores em razão de variações intertemporais nos salários reais. O nível de emprego não é uma decisão autônoma das empresas uma vez que a demanda de trabalho está baseada em uma relação técnica, em curvas de produção e custos definidas em razão da tecnologia disponível, do nível de produtividade e do preço dos fatores de produção, centralmente o trabalho. Por essa lógica fundada na predeterminada oferta de trabalho, para cada nível de salário real, as empresas sempre contratarão mais trabalhadores enquanto a receita marginal dada pela produção e venda de uma unidade adicional de produto - por hipótese, decrescente - for superior ao custo marginal dessa elevação da produção pelo emprego adicional - por hipótese, crescente. Para a lógica ortodoxa, as empresas sempre maximizaram o emprego em razão de seus custos de contratação que compõem seus custos marginais. Assim, se não contratam, trata-se de um problema de salários elevados que não compensam a ampliação da produção. Portanto, a oferta agregada de produtos é definida em determinado nível por culpa do preço dos fatores de produção, do principal deles, o trabalho.

Dessa forma, existiria tecnicamente uma relação ótima que conecta a demanda de trabalho à oferta de trabalho, esta última uma decisão dos trabalhadores. Assim é definida a taxa natural de desemprego. Qualquer desvio desse nível pressionaria os salários para cima, o que "obrigaria" os empresários a repassarem os aumentos aos preços dos produtos, gerando inflação. A inflação, portanto, é resultado da elevação do nível de emprego acima da taxa natural por uma interferência externa ao mercado de fatores. Por esse caminho, define-se ainda a taxa de crescimento do produto (PIB) potencial (produto natural - oferta agregada) em razão dos fundamentos microeconômicos que regem o mercado de trabalho: o comportamento racional autônomo dos trabalhadores em relação ao comportamento racional maximizador técnico das empresas.

Essa lógica teórica da "taxa natural de desemprego" substituiu o conceito 
clássico de pleno emprego que, de fato, não se encaixava na realidade. Mas não é muito diferente daquele desemprego discutido e criticado por Keynes (1982, p.25) em seu Teoria geral quando afirmava que, para o pensamento ortodoxo (que denominava "clássico"), só existia o desemprego voluntário, decisão dos trabalhadores - baseada na comparação entre a desutilidade marginal de trabalhar e a utilidade marginal do salário real ganho ou, que apenas haveria desemprego causado por "imperfeições de ajustamento" tais como: "desproporções dos recursos especializados", "cálculos errados" ou "mudanças imprevistas" (falhas de informação), "procura intermitente" (ciclo de negócios), conceitos que podem ser encaixados nas atuais teorias das "falhas de mercado" presentes na nova Síntese Neoclássica (Carvalho, 1987-1988).

Para a ortodoxia, a violação das taxas naturais de emprego e produto cria confusão nos mercados, o que dificulta seu ajuste natural via preços flexíveis no "ciclo de negócios" também natural da economia. Esse conceito de ciclo não tem nenhuma relação com crescimento e crise. Trata-se de um movimento pendular de ajustamento de ofertas e demandas via variação livre de preços nos diversos mercados de modo a garantir a ótima alocação dos recursos escassos. Assim, interferir nos mercados deixaria os agentes (trabalhadores, empresários e consumidores) confusos, sem saber se a variação nos preços é inflação ou sinal para ajustes necessários entre oferta e demanda. Acrescenta-se mais um fator psicológico ao contexto. A defesa da política de metas de inflação baseia-se na ideia de que é crucial não confundir os agentes. Soma-se a isso a ideia de que os mercados se autocorrigem de forma eficiente, como se houvesse uma inteligência hayekiana interna a eles.

Substituir o conceito de pleno emprego por taxas naturais de desemprego é providencial. Pleno emprego é um conceito concreto e definido, mesmo como um objetivo a ser alcançado: a menor taxa de desemprego possível no sentido de zero. Já o conceito de taxa de desemprego natural leva a discussão para um nível metafísico definido pela abstrata "racionalidade" dos trabalhadores, pela ideia de que são eles que têm o poder de definir salários e o volume de emprego. Também se baseia num conceito metafísico de empresário "racional e maximizador" da produção que Keynes havia destruído, assim como Marx, ao introduzir o dinheiro e a acumulação de capital como objetivos centrais, e não a máxima produção em razão dos custos dos fatores. Isso se torna ainda mais claro quando ninguém sabe qual é a taxa de desemprego natural: sua definição é alcançada por dedução a partir das hipóteses fundadas na ideia de racionalidade dos agentes - transformada em expectativas racionais. Para garantir a conclusão desejada, o caminho é estrategicamente invertido: a existência de inflação é o resultado de a taxa de desemprego estar fora do seu nível natural, ou seja, há mais trabalhadores empregados do que suporta a economia dada a tecnologia que define o nível de produto marginal e o salário real. Assim a inflação seria, por dedução, o resultado do desequilíbrio. Não se sabe qual é essa taxa de desemprego, mas 
deduz-se que se há inflação ou deflação (caso raro), o desemprego está fora de seu equilíbrio natural. Na verdade, esse conceito visa encobrir a discussão concreta sobre a existência de desemprego, uma vez que carrega a ideia de que não existe desemprego involuntário, a não ser no curtíssimo prazo, e os mercados (todos, incluindo o de trabalho) naturalmente encontram o equilíbrio.

O mais interessante é que essa questão estava no centro do debate na época de Keynes. Não é à toa que trata do assunto no capítulo 2 - praticamente o primeiro capítulo - de seu Teoria geral. Mas também já havia sido amplamente discutida por Marx de outra maneira no capítulo XXIII de O capital. Vale a pena recuperar os argumentos, uma vez que o debate atual sobre a questão se pauta entre a ortodoxia acima exposta de forma estilizada e a heterodoxia. O eixo da diferença está em que, para esses autores, o trabalhador não possui qualquer poder para definir de seu salário (real ou nominal), bem como são as empresas que determinam o nível de emprego a partir de suas decisões autônomas de investimento que dependem pouco (e às vezes nada) do custo do trabalho, mas dependem muito de suas decisões de investimento diante de um futuro incerto, envolvendo a disputa dinâmica entre capitais individuais ou corporações por controle e ocupação de mercados em sua estratégia de acumulação ampliada. Colocar o trabalho como "bode expiratório" do problema parece servir mais a objetivos ideológicos do que "técnicos".

\section{Mercado de trabalho a partir de Marx}

É interessante retornar aos clássicos para fazer frente à discussão dominada por um pensamento que se autodenomina de novo-clássico (centro da nova Síntese Neoclássica) e que tem sua base nos "marginalistas" (Walras) também do século XIX, de onde provêm os fundamentos do pensamento ortodoxo atual. Assim, voltar à discussão sobre o "mercado" de trabalho em Marx não parece uma heresia, mas demonstra que a discussão atual que ganhou determinados rumos é muito antiga e já foi feita com mais prudência. Vale a pena retomar o capítulo XXIII de $O$ capital:

A procura de trabalho não se identifica com o crescimento do capital, nem a oferta de trabalho com a classe trabalhadora. Não há duas forças independentes, uma influindo sobre a outra. É um jogo de dados viciados. O capital age ao mesmo dos dois lados. Se a acumulação aumenta a procura de trabalho aumenta também a oferta de trabalhadores [...] Nessas condições o movimento da lei da oferta e da procura de trabalho torna completo o despotismo do capital. (Marx, 1980, p.743)

A demanda e a oferta de trabalho seguem os desígnios da dinâmica do processo de acumulação e não os desejos de trabalhadores autônomos. Quando a economia cresce e amplia o processo de acumulação, eleva-se a demanda por trabalho vivo, o que pressiona os salários reais para cima. Sem desenvolvimento de novas tecnologias, essa pressão salarial diminui o trabalho excedente que constitui a mais-valia. É justamente essa pressão de custos que leva as empresas a 
investir em novas máquinas e tecnologias para substituir trabalho vivo (que pode ser apenas relativa e não absoluta, dado que ambos elevam-se no crescimento econômico), modificando a composição do capital num processo dinâmico. A inovação é impulsionada pela concorrência entre os capitais individuais em sua busca por diminuir o valor individual unitário das mercadorias que produzem em relação ao valor médio de seus concorrentes. Assim ganham em eficiência e superam seus concorrentes ao mesmo tempo que substituem o fator trabalho, mais caro, por máquinas e equipamentos mais modernos e mais baratos. É essa dinâmica que força a permanente busca por inovação e tecnologia e eleva a produtividade da economia como um todo; torna os produtos finais mais baratos, o que permite, se os ganhos de produtividade não forem repassados aos trabalhadores, uma diminuição relativa da participação dos salários no valor criado elevando-se a mais valia relativa para todos os capitais individuais.

A contradição dessa dinâmica está em que quando o capital se expande, dada a tecnologia, eleva a demanda por trabalho, mas quando realiza a inovação tecnológica que substitui trabalho por máquinas modernas, expulsa trabalhadores do processo, elevando também a oferta disponível de trabalho. Por isso, o capital atua tanto sobre a oferta como sobre a demanda de trabalho, bem como tem a tendência de, no processo, baratear a força de trabalho em relação ao valor criado, podendo diminuir a participação deste na renda nacional. Portanto, trata-se de um processo concentrador de renda quando não repassa os ganhos de produtividade ao trabalho e quando desemprega. No caso em que a renda é muito mal distribuída, mesmo que ocorresse uma elevação dos salários pela produtividade, a melhoria da distribuição só ocorreria se esse se elevasse acima da produtividade redefinindo a divisão do valor entre trabalho pago e excedente.

O processo descrito, além de estar sob controle do capital, tem, segundo Marx, uma tendência a expulsar mais trabalho da produção do que incorporar. O clássico de Jeremy Rifikin apontava para esse problema. Renova sua preocupação na nova introdução de seu livro de 2004 ao afirmar que

A antiga lógica de que os avanços tecnológicos e aumentos da produtividade destroem os velhos empregos criando novos já não vigora. A produtividade sempre foi vista [no pensamento ortodoxo] como um motor para a criação de empregos e prosperidade [...] A produtividade vem aumentando rapidamente nos EUA e, a cada passo, mais trabalhadores são dispensados. (Rifkin, 2004, p.xxi)

Ele mesmo aponta para a possibilidade de transferência de empregos para outros países como a China, mas ao apontar a expulsão como uma tendência do capital, deve também ocorrer na China. Além disso, completa que esse desemprego estrutural afeta os setores de serviços.

$\mathrm{Na}$ lógica de Marx, só seria possível elevar o emprego com ampliação do processo de acumulação sem precedentes e cada vez mais acelerado, o que não é apenas difícil como sempre desemboca em crises de superacumulação (excesso 
de capacidade produtiva) e subconsumo, este último como consequência da queda da participação do trabalho na renda. E mesmo assim, deve-se pensar em formas de distribuição de renda fora da lógica da acumulação ou do mercado.

Dessa forma, não existe realmente uma curva de oferta de trabalho definida pelos trabalhadores com capacidade de determinar seus salários. O que existe é uma pressão dinâmica constante para manter os salários sempre baixos conjugados a uma taxa de desemprego em um nível que não pressione as taxas de lucros das empresas. Isso talvez explique concretamente o que os economistas ortodoxos chamam de taxa natural de desemprego: aquela que não pressiona os lucros e não permite a distribuição de renda via elevação real de salários acima da produtividade.

\section{Mercado de trabalho e a crítica de Keynes}

Não é um mero acaso que a crítica radical ao mercado de trabalho neoclássico esteja logo no início da Teoria geral do emprego... A questão era central no debate da década de 1920 como é agora (Keynes publica o livro em 1936). Desfazer o mito de que a economia é a ciência da "alocação de recursos escassos" era essencial e está no primeiro parágrafo do capítulo 2 (Keynes, 1982). O primeiro objetivo foi demonstrar que o principal recurso, o trabalho, aquele que cria as próprias máquinas e desenvolve tecnologia, portanto toda a oferta, não é escasso por natureza. Demonstra que, mesmo considerando-se (em uma primeira aproximação) a curva de demanda de trabalho negativamente inclinada por conta da precária ideia de produto marginal decrescente, não há sentido em pensar uma curva de oferta de trabalho definida pelo poder ou desejo dos trabalhadores. A irrealidade é discutida em Lavoie (1992, cap.5, p.217-24) ao afirmar que "a curva de oferta agregada de trabalho pode ter qualquer formato" e mais do que isso "não afeta a análise do mercado de trabalho" (ibidem, p.224).

A inexistência de uma curva de oferta de trabalho deve-se fundamentalmente ao fato de que não é o trabalhador que define o volume de emprego, nem tampouco o nível de salários (Sicsú, 2003, p.160). Como não há outra forma de existência social dado que o trabalhador é desprovido de capital, só pode existir socialmente pela venda de sua força de trabalho. Ele não tem poder para decidir se trabalha ou não qualquer que seja o salário. Seu poder se restringe a comparar seu salário com outros em sua categoria. Além do mais, se de fato existe alguma desutilidade marginal do trabalho que o impeça de aceitar trabalhar, essa deve ser muito baixa dado que não há alternativa para garantir sua existência social.

É também discutível a existência de uma curva de demanda de trabalho negativamente inclinada em razão da "lei dos rendimentos decrescentes" - cada unidade de trabalho adicional criaria um produto adicional menor que o anterior (produto marginal decrescente) - base ainda de parte do pensamento ortodoxo. De um lado, isso só seria válido se não houvesse ganhos de escala mesmo no curto prazo (quanto mais se produz, menores os custos unitários), o que desde que Kalecki (1983, p.13) levantou o ponto seguindo Marx, parece 
o normal. Mesmo aceitando-se que o produto marginal seja decrescente, isso só valeria para o curto prazo em que as instalações fabris são dadas. No longo prazo, quando se trata de investimentos em estoque de capital (Keynes, 1982 p.125), as instalações podem ser ampliadas, portanto não estão restritas, e o nível tecnológico e a produtividade elevam-se. Assim, é discutível a existência da curva de demanda de trabalho negativa dada por relações técnicas de produção (produto marginal).

Dessa forma, o problema do emprego não está relacionado a esses mecanismos ou a uma lógica do mercado de trabalho. A demanda de trabalho é uma prerrogativa das empresas em razão de suas estratégias, do que esperam ganhar em termos monetários no futuro (Eficiência Marginal do Capital) quando decidem criar um volume de empregos que gerará determinado valor de produto (preço de oferta). Essa decisão relaciona-se à demanda agregada que esperam encontrar no futuro. As empresas não decidem o volume de emprego em razão do preço do trabalho no presente. O problema é quanto conseguirão vender no futuro, o que é, por natureza, incerto e depende da demanda agregada no futuro, desconhecida. A expectativa de um salário baixo no futuro pesa negativamente sobre a decisão das empresas, uma vez que supõe um consumo futuro inferior.

Isso significa que se decidirá empregar um número de trabalhadores não em função da oferta de trabalho "[...] os trabalhadores, em conjunto, não dispõem de nenhum meio de fazer coincidir o equivalente de nível geral de salários nominais expressos em bens de consumo com a desutilidade marginal do volume de emprego existente" (Keynes, 1982, p.30).

É a expectativa de futuro e não o volume de fatores de produção ou o volume de trabalhadores disponíveis a trabalhar que determina o tamanho do investimento e quantos trabalhadores serão contratados. Ao contrário, não há nenhuma relação com a oferta de emprego, mas com a demanda agregada futura esperada. Assim, podem decidir empregar um volume de fatores de produção inferior ao disponível (trabalhadores que desejam trabalhar pelo salário vigente) porque não acreditam que encontrarão demanda no futuro para um investimento maior. Decidem assim o tamanho da sua estrutura produtiva. As empresas não sabem qual será o tamanho do consumo no futuro porque este depende do emprego criado em conjunto e, principalmente, não sabem qual será o tamanho do investimento no futuro (demanda de bens de produção), uma vez que dependerá da nova decisão das empresas no futuro, essa sim, muito mais incerta.

Pela lógica da própria acumulação de capital, não há como determinar se o emprego está em um hipotético "nível natural", tampouco imaginar que por decisões microeconômicas, por mais racionais que sejam, se alcançaria o nível de pleno emprego. Não existe taxa natural de desemprego, assim como não existe o equilíbrio imaginário no mercado de trabalho. $\mathrm{O}$ poder de decisão não está nas mãos de trabalhadores, mas nas mãos das empresas que tomam suas decisões de investimento em função de suas expectativas de futuro que Keynes (1982, p.38) 
denominou "demanda efetiva". Portanto, o volume de emprego que será criado tem pouca ou nenhuma relação com o conceito "ortodoxo" de mercado de trabalho. É uma decisão de investimento, transformação do dinheiro em capital produtivo, tomada unilateralmente pelo empresário capitalista. É o investimento que determina o nível de emprego.

O pensamento ortodoxo tentou transformar essas expectativas (incerteza radical) em algo conhecido em contradição com o próprio termo ao transformá-la em racional, segundo a qual os agentes ao conhecer a correta teoria econômica, o funcionamento natural da economia, saberiam o que ocorrerá no futuro e antecipariam suas decisões. O futuro tornou-se totalmente conhecido. Indo além, como os agentes (empresas e trabalhadores) conhecem o princípio das taxas naturais, sabem que sua violação causaria inflação. Por esse caminho, o governo, ao garantir que não violará a lógica da natureza econômica - como pretende o governo atual no Brasil -, faria que as expectativas racionais conduzissem as ações dos empresários e os mercados aos seus níveis naturais de equilíbrio dinâmico. Sem inflação, a variação de preços relativos nos "ciclos de negócios" serviria para sinalizar a melhor alocação dos fatores de produção nos diversos setores da economia. O crescimento econômico ocorreria naturalmente dentro dos limites das taxas naturais de desemprego e produto. Portanto, não existe a "questão do desemprego" para a ortodoxia, nem problemas de distribuição de renda.

\section{Como elevar o emprego?}

O crescimento econômico no capitalismo depende da decisão dos empresários investirem, e não da decisão dos trabalhadores trabalharem ou não. São as próprias empresas que ao investirem em conjunto decidem o quanto a economia crescerá, e quanto emprego será gerado. Não existem taxas naturais. Existe um processo dinâmico de disputa pelo valor entre trabalho e capital com clara desvantagem para o primeiro que dispõe apenas de si mesmo como forma de existência econômica e social. A contradição é que essa disputa pode ser inflacionária: os empresários repassam as elevações salariais aos preços. Em uma economia oligopolizada isso é normal. De outro lado, a necessidade de expansão imposta pela lógica da acumulação pressiona cada empresa para a frente num mecanismo fundado na disputa pelo valor excedente global (mais-valia) e pelo espaço de acumulação, obrigando cada capital individual a investir em modernização, substituir trabalho vivo por máquinas. A maior ou menor criação de empregos depende dessas dinâmicas do capital.

A ideia ortodoxa de manter sempre abundante a oferta de desempregados que denomina de "taxa natural de desemprego" serve para evitar que ocorram pressões salariais nesse processo de disputa desigual pela riqueza. Contraditoriamente, a desigual distribuição de renda dificulta o crescimento econômico, a própria acumulação de capital em seu sentido expansivo. Contribui ainda para impedir o investimento em inovação e tecnologia que resulta das próprias pres- 
sões salariais sobre o lucro das empresas. Assim, essa ideia, apesar de microeconomicamente lógica, impede o próprio investimento e crescimento. Além disso, impacta sobre o mercado consumidor, o que atrapalha ainda mais as expectativas de demanda futura das empresas. Ao contrário, como se pode ver hoje no Brasil, os investimentos caem alimentando ainda mais as expectativas negativas. $\mathrm{O}$ desemprego cresce.

Isso significa que o problema do emprego está antes de tudo relacionado a como se percebe a lógica do funcionamento da economia capitalista. $\mathrm{O}$ atual ministro da Economia navega na lógica teórica ortodoxa neoclássica e não cansa de repetir que rapidamente, retomados os fundamentos da nova síntese neoclássica, as expectativas racionais se restabeleceriam e os investimentos de forma automática cresceriam respeitando-se as taxas naturais de emprego e produto. Assim, acusa o governo de ter, nos anos de crescimento do emprego, enganado os trabalhadores (Friedman, 1988, p.431) ao ter tirado a economia do equilíbrio dado pelas taxas naturais, por meio de políticas econômicas "populistas".

Essa "irresponsabilidade" do governo nos anos passados teria causado uma imaginária tendência aceleracionista das taxas de inflação - imaginária porque não existia até a adoção das políticas restritivas de 2015. Segundo essa lógica, mantidas as políticas expansionistas por muito tempo, o país teria caminhado para uma inflação em uma espiral ascendente de preços e salários. A solução proposta foi a de forçar a economia a retornar à hipotética taxa de desemprego natural acreditando que com isso estaria garantida a retomada da confiança por parte dos agentes e o mecanismo de preços como fator de excelência na alocação dos recursos escassos. Os empresários, diante de um cenário estabilizado, como autômatos maximizadores, investiriam, o que elevaria a produtividade e criaria novos empregos dado que os salários reais poderiam ser maiores e mais pessoas desejariam trabalhar,

[...] celebrando o otimismo da teoria econômica tradicional - que levou os economistas a serem considerados como cândidos, os quais, tendo-se retirado do mundo para cultivarem seus jardins, clamam que tudo caminha do melhor modo no melhor dos mundos possíveis, contudo que deixemos as coisas andarem sozinhas... (Keynes, 1982 p.44)

Pelo exposto, procurou-se deixar claro que a única solução para o problema do desemprego é o crescimento econômico. Para isso é preciso investimentos. As empresas só investem em razão de estratégias de concorrência pelo espaço de acumulação (Marx) e das expectativas de vender suas mercadorias pelo preço de oferta desejado, encontrando uma curva de demanda agregada no futuro elevada (Keynes). Essa expectativa depende do nível de consumo que encontrarão no futuro (nível de renda dos trabalhadores), bem como de se as empresas no futuro continuarão investindo (comprarão a produção passada), se continuarão otimistas e serão pressionados por suas estratégias de mercado a modernizarem-se. 
Mesmo diante desse cenário, nada garante que o crescimento do emprego resultará em melhora na distribuição de renda em favor do trabalho. A tendência é a concentração no sentido da mais-valia (lucros, juros e aluguéis). Em uma economia estruturalmente desigual como a brasileira, não basta o emprego para melhorar a distribuição de renda. Os mecanismos capitalistas de pressão para elevação dos salários reais não funcionam, não somente por conta da lógica exposta por Marx, mas porque as empresas têm forte poder de repassar custos aos preços, gerando inflação e impedindo a distribuição da renda via salários.

A única forma de retomar o crescimento seria pela mudança de sinal por parte do governo - o sinal atual é de recessão - para as empresas retomarem os investimentos, principalmente a indústria que ficou à margem do crescimento anterior diante do sonho de que o país pudesse crescer e se desenvolver retornando à condição de primário exportador focado em soja e minério de ferro. Uma das formas para iniciar essa sinalização aos empresários é a retomada dos investimentos públicos em projetos de infraestrutura. Se os $3 \%$ do PIB de acréscimo de pagamento de juros (passou de $5 \%$ para $8 \%$ ) sobre a dívida pública fossem todos para a infraestrutura, a realidade seria completamente diferente. Com o crescimento econômico, se elevaria também a arrecadação de impostos para fazer frente às políticas sociais que representam muito pouco do orçamento e são cruciais na distribuição de renda. Apesar dos possíveis e normais aumentos salariais pela pressão sobre a demanda de trabalho, as empresas não apenas ganhariam com o aumento do consumo, necessitando repassar menos aos preços e diminuindo a pressão inflacionária, como também seriam impulsionadas a investir em novas tecnologias para elevar a produtividade, como em um sistema capitalista de verdade.

De qualquer forma, só é possível resolver ambos os problemas pondo fim à lógica ortodoxa neoclássica que tomou conta da burocracia de Estado fundada em argumentos microeconômicos que não servem para entender a complexidade macroeconômica, mas que servem para carrear renda interna para os grupos de rentistas que esses economistas no poder representam.

Cada vez fica mais claro que derrotar a ortodoxia é principalmente derrotar uma estrutura de poder que se enraizou no bloco de poder que encontra espaço para ocupar de forma mais contundente as instituições de Estado.

\section{Notas}

1 Apenas como comparação, no ápice do crescimento do PIB e do PAC, o Brasil investia $2 \%$ do PIB em infraestrutura. Com a política de juros atuais, gastamos $3 \%$ do PIB e cortamos infraestrutura.

2 Veja entrevistas de três economistas no jornal O Estado de S. Paulo, 30.8.2015, p.B4 e B5.

3 Refere-se ao modelo IS-LM fundado pelos economistas Hicks, Hansen, Samuelson. 
Referências

BRESSER-PEREIRA, L. C. A construção politica do Brasil: sociedade, economia e Estado desde a Independência. São Paulo: Editora 34, 2014.

CARVALHO, F. C. Da síntese neoclássica à redescoberta de Keynes. Análise econômica, Porto Alegre, ano 6, n.9, p.3-21, nov. 1987-mar. 1988.

Equilíbrio fiscal e política econômica. Revista Análise Econômica, Porto Alegre, ano 26, n.50, p.7-25, set. 2008 .

FRIEDMAN, M. Inflação e desemprego: a novidade da dimensão política. In: Clássicos da literatura econômica. Rio de Janeiro: Ipea/Inpes, 1988. p.381-448.

KALECKI, M. Teoria da dinâmica econômica: Ensaio sobre as mudanças cíclicas e a longo prazo da economia capitalista. São Paulo: Abril Cultural, 1983.

KEYNES, J. M. A teoria geral do emprego, do juro e da moeda. São Paulo: Atlas, 1982.

LAVOIE, M. Foundations of Post-Keynesian Economic Analysis. Cheltenham: Edward Elgar, 1992.

2006.

Introduction to post-Keynesian Economics. New York: Palgrave Macmillan,

MARX, K. O capital Livro 1: o processo de produção do capital. Rio de Janeiro: Civilização Brasileira, 1980.

RIFKIN, J. O fim dos empregos: o contínuo crescimento do desemprego em todo mundo. São Paulo: M. Books, 2004.

SICSÚ, J. Keynes e os novos-keynesianos. In: LIMA, G.T. Macroeconomia do emprego e da renda: Keynes e o keynesianismo. Barueri: Manole, 2003.

SNOWDON, B.; VANE, H. R. Modern macroeconomics: its origins, development and current state. Cheltenham: Edward Elgar, 2005.

RESUMO - A discussão sobre o crescimento econômico e o emprego no Brasil está bloqueada por uma teoria importada, baseada nas "taxas naturais" de emprego, ideia criada por Friedman que hoje invade a teoria econômica no mundo. Essa visão equivocada está impondo ao país uma brutal recessão com crescimento do desemprego e queda na produção agregada sem qualquer sucesso naquilo que se propõe: recuperar uma credibilidade metafísica por parte das empresas. Trata-se de uma questão de poder político de um determinado grupo social que hoje extravasa os partidos políticos.

PALAVRAS-CHAVE: Desemprego, Desenvolvimento econômico, Heterodoxia.

ABSTRACT - The discussion on economic growth and employment in Brazil has been stanched by an imported theory based on "natural rates" of employment - an idea developed by Milton Friedman that today pervades economic theory around the world. This mistaken view is imposing upon the country a brutal recession, with rising unemployment and a drop in aggregate production, without showing any sign of success in 
what it proposes, namely, a metaphysical recoup of credibility on the part of companies. It is actually a matter of political power of a particular social group that today extends beyond political parties.

KETWORDS - Unemployment, Economic development, Heterodoxy.

Rubens R. Sawaya é professor da Pós-Graduação em Economia Política, Departamento de Economia da PUC-SP. @ - rrsawaya@gmail.com

I Departamento de Economia, Pontifícia Universidade Católica, São Paulo/São Paulo, Brasil.

Recebido em 8.9.2015 e aceito em 18.9.2015. 
